\title{
The Effect of Casein Ingestion within a Milk Matrix on Muscle Protein Synthesis
}

\author{
Sarah Reiners \\ Department of Human Movement Science \\ s.reiners@student.maastrichtuniversity.nl
}

\begin{abstract}
Isolated micellar casein has been classified as a slow protein because of its slow digestion and amino acid absorption kinetics. These result further in a more moderate and sustained amino acid availability in the plasma and subsequently lower muscle protein synthesis (MPS) rate when, for example, compared with whey. However, the milk matrix with lactose, fat and various minerals may modulate the effect of casein on MPS. Therefore, this study aimed to compare the effects of the ingestion of casein dissolved in bovine milk serum to the ingestion of isolated casein on myofibrillar protein synthesis. In this parallel group randomized trial, 32 healthy older men (age: $71 \pm 1 \mathrm{y}$ ) received a primed continuous infusion of $\mathrm{L}-\left[\right.$ ring $\left.^{-2} \mathrm{H}_{5}\right]$ phenylalanine, $\mathrm{L}-\left[1-{ }^{13} \mathrm{C}\right]$ leucine, and $\mathrm{L}-\left[\right.$ ring $\left.-3,5^{-2} \mathrm{H}_{2}\right]$ tyrosine and blood and muscle samples were taken to assess myofibrillar fractional synthetic rate (FSR) under basal postabsorptive conditions and after a single bolus of $25 \mathrm{~g}$ intrinsically $\mathrm{L}-\left[1{ }^{-{ }^{13} \mathrm{C}}\right]$ phenylalanine and $\mathrm{L}-\left[\mathrm{1}^{13} \mathrm{C}\right]$ leucine-labeled casein either in an isolated form (ISOCAS; $n=16$ ) or dissolved in bovine milk serum (MILK-CAS; $n=16$ ). The ingestion of $25 \mathrm{~g}$ of casein significantly $(P<0.05)$ increased MPS rates in both groups when assessed over the late postprandial period $(t=120-300 \mathrm{~min}$ ). Ingestion of MILK-CAS and ISO-CAS did not significantly stimulate MPS rates when assessed over the early ( $t=0-120 \mathrm{~min}$ ) and overall $(\mathrm{t}=\mathrm{O}-300 \mathrm{~min}$ ) postprandial FSR compared to postabsorptive $(\mathrm{t}=-120-0 \mathrm{~min}) \mathrm{FSR}$. No significant differences were observed between the two groups over the early, late or entire postprandial period $(P>0.05)$. The ingestion of additional normal milk matrix to micellar casein does not modulate overall myofibrillar protein synthesis rates in older men when compared to the ingestion of micellar casein dissolved in water. Therefore, there is neither a benefit, nor a detrimental effect of ingesting micellar casein within a normal milk matrix instead of the isolated form to increase MPS.
\end{abstract}




\section{Keywords}

casein, milk matrix, muscle protein synthesis rate, dietary protein, sarcopenia, elderly.

\section{Introduction}

Dairy products contain high amounts of proteins and are widely available, so that they can easily be included in everyday nutrition. Ingestion of casein, one of the milk proteins, can result in prolonged hyperaminoacidemia, resulting in an increase in MPS (1). Furthermore, casein ingestion can also inhibit whole body protein breakdown (2). Until now, research has examined the effect of casein on MPS by using an isolated form of casein extracted from the milk matrix in which it normally resides. However, lactose, fat and various minerals in milk may modulate the effect of casein on MPS (3). Therefore, the aim of this study was to examine the muscle protein synthetic response following dietary casein intake in the isolated form and within the normal milk matrix in elderly men. It was hypothesized that casein within a normal milk matrix stimulates myofibrillar protein synthesis rates more effectively than isolated casein because milk has the capacity to buffer the gastric acid (4). A higher buffering capacity may lead to a more alkaline environment in the stomach, thereby reducing the clotting of casein, leading to a greater bioavailability of caseinderived amino acids and a subsequent higher postprandial MPS rate.

\section{Material and methods}

A total of 32 healthy, elderly men ( $>65 \mathrm{y}$ ) were selected to participate in this parallel group randomized trial.

\section{Pretesting}

Before participation, the healthy males with an age higher than 65 years and a BMI below $30 \mathrm{~kg} \cdot \mathrm{m}^{2}$ underwent a medical screening to assess their glycosylated hemoglobin ( $\left.\mathrm{Hb} \mathrm{A}_{1 \mathrm{c}}\right)$, glucose tolerance (by a 2-hour oral glucose tolerance test) according to 2006 American Diabetes Association guidelines (5), blood pressure, weight, height, and body composition. The body composition was determined by dual-energy X-ray absorptiometry (Discovery A; Hologic, Bedford, MA). All subjects were considered to be healthy based on their responses on the medical screening questionnaire and the results of the screening. The subjects were randomly divided to consume either isolated casein dissolved in water (ISO-CAS) or isolated casein dissolved in bovine milk serum (MILK-CAS). The randomization of these two groups was computer generated (www.randomization.com) and the participants, researchers, and technicians were blinded to the group allocation. The beverages were prepared by an independent researcher assistant by using codes. 
Diet and physical activity before testing

Every subject received a standardized meal the evening before the test containing 55 $\%$ energy as carbohydrates, $30 \%$ energy as fat, and $15 \%$ energy as proteins. After the ingestions of the meal, the subjects were asked to stay fasted until the morning of the test. All the subjects were also instructed to refrain from exhaustive physical activity for 2 days before the experimental day and to fill out nutrition and activity diaries for the 2 days prior the test day.

\section{Protocol}

Subjects reported to the laboratory at $0800 \mathrm{AM}$ following an overnight fast. One Teflon catheter was inserted into an antecubital vein for stable isotope infusion of L- $\left[\mathrm{ring}_{-}{ }^{2} \mathrm{H}_{5}\right]$ phenylalanine, $\mathrm{L}-\left[\mathrm{1}^{-13} \mathrm{C}\right]$ leucine, and $\mathrm{L}-\left[\right.$ ring $\left.-3,5^{-2} \mathrm{H}_{2}\right]$ tyrosine. A second Teflon catheter was inserted into a dorsal hand vein of the contralateral arm. This arm was placed in a hot box $\left(60^{\circ} \mathrm{C}\right)$ prior to each blood sample for arterialized blood sampling (6). After the collection of a first baseline blood sample $(t=-240)$, the plasma phenylalanine, leucine, and tyrosine pools were primed with a single intravenous dose of $\mathrm{L}-\left[\mathrm{ring}^{-2} \mathrm{H}_{5}\right]$ phenylalanine $\left(2 \mu \mathrm{mol} \cdot \mathrm{kg}^{-1}\right), \mathrm{L}^{-}\left[{ }^{-13} \mathrm{C}\right]$ leucine $\left(4 \mu \mathrm{mol} \cdot \mathrm{kg}^{-1}\right)$, and L-[ring $\left.-3,5^{-2} \mathrm{H}_{2}\right]$ tyrosine $\left(0.615 \mu \mathrm{mol} \cdot \mathrm{kg}^{-1}\right)$ after which a continuous infusion of L-[ring- $\left.{ }^{2} \mathrm{H}_{5}\right]$ phenylalanine $\left(0.05 \mu \mathrm{mol} \cdot \mathrm{kg}^{-1} \cdot \mathrm{min}^{-1}\right), \mathrm{L}-[1-$ $\left.{ }^{13} \mathrm{C}\right]$ leucine $\left(0.10 \mu \mathrm{mol} \cdot \mathrm{kg}^{-1} \cdot \mathrm{min}^{-1}\right)$, and $\mathrm{L}-\left[\mathrm{ring}-3,5^{-2} \mathrm{H}_{2}\right]$ tyrosine $\left(0.015 \mu \mathrm{mol} \cdot \mathrm{kg}^{-1} \cdot \mathrm{min}^{-1}\right)$ was started. The subjects rested in a supine position during the entire experiment. Four muscle biopsies were taken $(t=-120, t=0, t=120, t=300$ ) for the determination of postabsorptive $(t=-120-0 \mathrm{~min})$, early $(t=0-120 \mathrm{~min})$, late $(t=120-300 \mathrm{~min})$ and overall $(t=0-$ $300 \mathrm{~min}$ ) postprandial myofibrillar protein synthesis rates. The biopsies were taken from the middle region of the $m$. vastus lateralis, $15 \mathrm{~cm}$ above the patella and $3 \mathrm{~cm}$ below the entry through the fascia, by using a Bergstrom needle under local anesthesia (7). Until further analysis all muscle biopsy samples were freed from any visible fat tissue and blood, frozen in liquid nitrogen and stored at $-80^{\circ} \mathrm{C}$. Immediately after the second biopsy $(t=0)$, all subjects ingested a single bolus of $25-\mathrm{g}$ intrinsically $\mathrm{L}-\left[1{ }^{-13} \mathrm{C}\right]$ phenylalanine and $\mathrm{L}-\left[1^{-13} \mathrm{C}\right]$ leucine-labeled casein dissolved either in water or in bovine milk serum. The total beverage contained $600 \mathrm{ml}$. The milk serum was diluted down to a concentration of $5 \%$ lactose, which is typical for bovine milk. After that several blood samples ( $t=15, t=30, t=$ $45, t=60, t=90, t=120, t=150, t=180, t=240, t=300$ ) were collected during the infusion.

Intrinsically labeled protein and tracer infusion

Intrinsically $\mathrm{L}-\left[1^{-13} \mathrm{C}\right]$ phenylalanine and $\mathrm{L}-\left[1^{-13} \mathrm{C}\right]$ leucine casein was obtained by infusing a Holstein cow with large amounts of $L-\left[1^{-13} \mathrm{C}\right]$ phenylalanine and $\mathrm{L}-\left[1-{ }^{13} \mathrm{C}\right]$ leucine and 
collecting the milk. The milk was further converted to skim milk by heating. The skim milk was microfiltrated on a $0.2 \mu \mathrm{M}$ pore size diameter membrane to separate the casein micelles from the soluble whey proteins at $55^{\circ} \mathrm{C}$. The $\mathrm{L}-\left[1^{-13} \mathrm{C}\right]$ phenylalanine and $\mathrm{L}-\left[1^{-13} \mathrm{C}\right]$ leucine enrichment in the casein fraction averaged 38.7 mole percentage excess (MPE) and 9.3 MPE, respectively. The casein protein met all chemical and bacteriologic specifications for human consumption. The stable isotope tracer $\mathrm{L}-\left[\right.$ ring $\left.^{-2} \mathrm{H}_{5}\right]$ phenylalanine and $\mathrm{L}-\left[{ }^{-13} \mathrm{C}\right]$ leucine were purchased from Cambridge Isotopes and dissolved in $0.9 \%$ saline before infusion. For the constant intravenous infusions a calibrated IVAC 598 pump (San Diego, CA) was used. The tracers were prepared by the pharmacy of the Maastricht University Medical Center.

\section{Plasma and muscle tissue analysis}

Plasma glucose and insulin concentrations were analyzed with the use of commercially available kits (GLUC3; roche, Ref: 05168791 190, and Immunologic; Roche, Ref: 12017547 122, respectively). Plasma amino acid concentrations and enrichments were determined by using gas chromatography/mass spectrometry (GC-MS; Agilent 7890A GC/5975C; MSD, Little Falls, DE). Myofibrillar protein-bound L- $\left[\right.$ ring $\left.^{-2} \mathrm{H}_{5}\right]$ phenylalanine enrichments were determined by GC-MS analysis and the L-[133 $]$ phenylalanine and L-[1-13C]leucine enrichments by gas chromatography combustion isotope ratio mass spectrometry (GCC-IRMS) analysis.

\section{Calculations}

The standard precursor product equation was used to calculate the FSR of the myofibrillar proteins:

$$
F S R=\frac{\Delta E p}{\text { Eprecursor } \times t} \times 100 \%
$$

where $\triangle E P$ is the difference in myofibrillar protein-bound $\mathrm{L}-\left[1^{13} \mathrm{C}\right]$ leucine or $\mathrm{L}-\left[\right.$ ring $\left.^{-2} \mathrm{H}_{5}\right]$ phenylalanine between two muscle biopsies, Eprecursor is the average plasma $\mathrm{L}-\left[\mathrm{1}^{13} \mathrm{C}\right]$ leucine or $\mathrm{L}-\left[\right.$ ring $\left._{-}{ }^{2} \mathrm{H}_{5}\right]$ phenylalanine enrichment during the incorporation period, and indicated the time interval $(\mathrm{h})$ between two biopsies.

\section{Statistics}

All data are expressed as means \pm SEMs. Baseline subject characteristics were compared with use of an unpaired $t$ test. The time-dependent variables of plasma amino acid enrichments and the differences in myofibrillar protein FSR between ISO-CAS and MILKCAS were analyzed by two-factor repeated-measures ANOVA. Two-factor repeated- 
measures ANOVA was conducted with group as the between-subjects factor (ISOCAS and MILK-CAS) and time as the within-subjects factor $(t=-120-300)$. In case of a significant interaction, a Tukey post hoc test was applied to identify pairwise differences. All calculations were performed by using SPSS 21.0 (SPSS, Inc., Chicago, IL) and statistical significance was set at $P<0.05$.

\section{Results}

In the postabsorptive period ( $t=-120-0 \mathrm{~min}$ ) no L-[1-13 C]phenylalanine enrichment was detected in the plasma in both groups. After the ingestion of the $25 \mathrm{~g}$ of doubly labeled micellar casein the plasma L-[1-13C]phenylalanine enrichment increased significantly in both groups and the enrichments remained elevated for the next $300 \mathrm{~min}$ in the postprandial phase $(P<0.05)$. Both groups reached a peak of $\sim 11.5$ MPE $(11.23 \pm 3.317$ MPE for ISO-CAS and $11.92 \pm 2.179$ MPE for MILK-CAS), whereby the peak of ISO-CAS was obtained earlier ( $t=87 \mathrm{~min}$ ) than for MILK-CAS $(t=139 \mathrm{~min})$. Significant differences between the groups were found at $t=45, t=60, t=180$, and $t=240(P=0.049, P=0.039, P=0.048$, and $P$ $=0.044$, respectively), whereby for the first two significantly different time points ISO-CAS resulted in higher enrichments than MILK-CAS and for the last two time points MILK-CAS resulted in higher enrichments (Fig. 1A).

Myofibrillar L- $\left[1^{13} \mathrm{C}\right]$ phenylalanine enrichments increased significantly over time $(P<0.05)$ in both groups, but there were no significant differences found between the groups. Myofibrillar L-[1-13C]phenylalanine enrichments at $t=120$ were $0.002 \pm 0.001$ and $0.003 \pm$ 0.001 MPE and at $t=3000.016 \pm 0.002$ and $0.015 \pm 0.002$ MPE for ISO-CAS and MILK-CAS, respectively (Fig. 1B).

There was a main effect of time obtained for the FSR based on both tracers $(P<0.001)$ (Fig. 1C, 1D). The late postprandial FSR $(t=120-300 \mathrm{~min})$, with mean plasma L- $\left[\mathrm{ring}^{-}{ }^{2} \mathrm{H}_{5}\right]$ phenylalanine enrichment as the precursor, reached values of $0.046 \pm 0.003 \% \cdot h^{-1}$ for ISOCAS and $0.041 \pm 0.003 \% \cdot h^{-1}$ for MILK-CAS and this was significantly different from the postabsorptive $(t=-120-0 \mathrm{~min})(P<0.001)$ and from the early postprandial $(t=0-120$ $\min )(P<0.001)$ FSRs. There were no significant differences obtained between the groups at any time point $(P=0.605$ ) (Fig. $1 \mathrm{C})$. While there is a steady increase in FSR for MILK-CAS $(+22.58 \%$ and $+36.84 \%)$, the early postprandial FSR decreased after the ingestion of the protein in the ISO-CAS group (-24.39\%), but increased then the more (+116.13\%) (Fig. 1D). In the late postprandial period a FSR of $0.067 \pm 0.004 \% \cdot h^{-1}$ for the ISO-CAS group was reached and a FSR of $0.052 \pm 0.004 \% \cdot h^{-1}$ for the MILK-CAS group. 

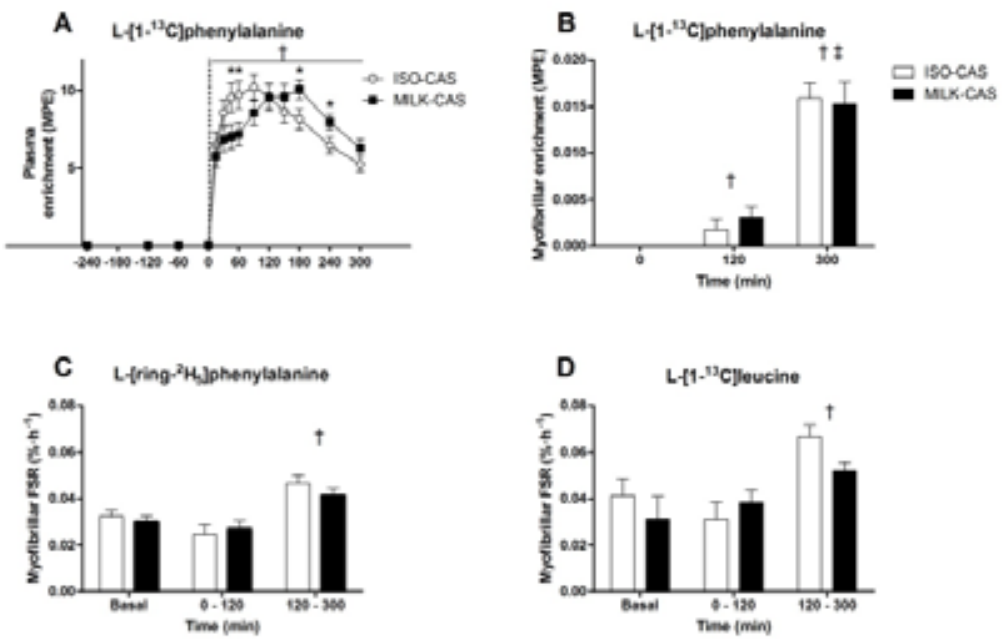

Figure 1. A) Mean \pm SEM plasma L-[1-13C]phenylalanine enrichments expressed as mole percentage excess (MPE). Vertical line represents the time point of protein intake. *Significant difference between the groups, $\mathrm{P}<0.05$. Significantly different from the postabsorptive plasma enrichments at that time point, $\mathrm{P}<0.05$. B) Mean \pm SEM myofibrillar L-[1 $\left.{ }^{13} \mathrm{C}\right]$ phenylalanine enrichment expressed as mole percentage excess (MPE). †Significantly different from $t=0, P<0.008$. $\neq$ significantly different from $t=120, P<0.001$. $C+D$ ) Mean \pm SEM myofibrillar fractional synthetic rates (FSR) with muscle L-[ring- $\left.{ }^{2} \mathrm{H}_{5}\right]$ phenylalanine (C) and L-[1-13C] leucine $(D)$ enrichments as precursor, represented over time with basal $(-120-0)$, early $(0-120)$ and late (120 - 300) values. ISO-CAS, isolated casein dissolved in water. MILK-CAS, isolated casein dissolved in bovine milk serum. †Significantly different from $t=-120-0$ and $t=0-120, P<0.001$.

\section{Discussion}

The present study investigated the effect of casein ingestion either in the isolated form dissolved in water or in the isolated form dissolved in bovine milk serum on MPS rate in healthy older men. We observed that ingesting casein increases the myofibrillar protein fractional synthesis rate, but casein dissolved in bovine milk serum does not modulate MPS rate when compared to ingesting casein in water.

The ingestion of casein dissolved in water resulted in an earlier rise in dietary-protein derived amino acids in the circulation, as indicated by plasma $L-\left[-1-{ }^{13} \mathrm{C}\right]$ phenylalanine enrichments, when compared to the ingestion of casein in milk serum (Fig. 1A). This indicates that co-ingestion of bovine milk serum might have reduced or delayed the digestion and absorption of casein. However, it was hypothesized that casein ingestion in the bovine milk serum may result in a faster digestion and absorption due to buffering 
mechanisms. Nevertheless, we did not observe that isolated casein within a normal milk matrix leads to an earlier rise in plasma amino acids derived from dietary protein. Furthermore, a delayed peak of the plasma L-[1-13C]phenylalanine enrichments in the MILK-CAS group was observed. This fact, however, can be attributed to the higher amount of calories like Calbet et al. (8) already showed. Because of lactose, a carbohydrate source, in the bovine milk serum, there is a reduced gastric emptying rate so that the digestion and absorption of the casein is delayed. This result is also consistent with the results of Gorissen et al. (9) who demonstrated that the co-ingestion of carbohydrates leads to a delayed protein digestion and absorption in young and older men. Therefore, the higher amount of calories delays the digestion and absorption of the casein that was dissolved in the bovine milk serum and this influences the digestion and absorption even stronger than the buffering capacity of the milk matrix does.

Several researches already showed that the rate of dietary protein digestion and absorption and the subsequent splanchnic amino acid extraction determines the postprandial amino acid delivery to the periphery $(10,11)$. The postprandial plasma amino acid availability has been shown to be an important regulator of postprandial muscle protein metabolism (1215). In line with two other studies that compared the effects of the ingestion of hydrolyzed protein and intact protein (11) and the effects of the ingestion of minced beef and beef steak (16) on mixed muscle protein FSR, a tendency can be seen that the more complex and intact the nutrition is and the more ingredients the nutrition contains, the slower is the digestion and the absorption. This results in a reduced or delayed plasma amino acid availability that further ends up in a reduced MPS rate. Therefore, it could be expected, with the results of the plasma $\mathrm{L}-\left[1^{1{ }^{13}} \mathrm{C}\right]$ phenylalanine enrichments, that there also will be a delayed or lower FSR in the MILK-CAS group compared to the ISO-CAS group.

The myofibrillar enrichments of $\mathrm{L}-\left[\mathrm{1}^{1{ }^{13}} \mathrm{C}\right]$ phenylalanine gives an indication of the amount of the dietary amino acids that was orally ingested and that was incorporated in the myofibrillar fraction of the muscle because this labeling type of phenylalanine derived only from the protein beverage. Myofibrillar L-[1-13C]phenylalanine enrichments increased over time, with no differences being observed between ISO-CAS and MILK-CAS (Fig. 1B). These data provide further evidence that a normal milk matrix does not result in a faster digestion and absorption of dietary protein or lead to a greater MPS rate in the postprandial state. Although the carbohydrates (lactose) present in the bovine milk serum may have had an influence on gastric emptying, there was no delayed appearance of dietary-protein derived amino acids in the muscle. Moreover, no group-effect was observed for the FSRs 
(Fig. 1C, 1D). Gorissen et al. (9) did not only show that the co-ingestion of carbohydrates with proteins results in a delayed digestion and absorption rate, but also that this fact does not further modulate postprandial MPS rate. Another study has also detected differences in protein digestion and absorption that had no further impact on the muscle protein synthetic response to protein ingestion (17). These results are actually in line with the results of this study.

Because of the fact that there is a tendency that the differences between the two experimental groups are getting bigger in later postprandial periods (Fig. 1C, 1D), it can be hypothesized that after 300 minutes after the intake of the protein drink, the myofibrillar FSR can increase even more and that the difference between the groups can also increase. Therefore, more research is warranted to assess the potential differences in the postprandial myofibrillar protein synthetic response to the ingestion of isolated casein compared with isolated casein within a normal milk matrix during a more expended time period. Moreover, there are some facts that confirm this hypothesis. First, there were no significant differences obtained between the basal $(t=-120-0 \mathrm{~min})$ and the early postprandial ( $t=0-120 \mathrm{~min}$ ) FSRs (Fig. $1 \mathrm{C}, 1 \mathrm{D})$ and secondly, there were also no significant differences found between the basal and the total postprandial $(t=0-300$ min) FSRs. The muscle biopsies were taken after 2 and after 5 hours of the ingestion of the protein drink, so that the time differences for the late postprandial period is greater than for the early postprandial period. This results in a more inaccurate calculation of the late postprandial FSR when compared to the postabsorptive and the early postprandial FSRs. Further research can therefor investigate the FSRs that are calculated with the same time intervals between the muscle biopsies (after 2.5 hours and after 5 hours) or the FSRs after 2,4 and 6 hours of protein ingestion.

In conclusion, the ingestion of casein increases myofibrillar protein fractional synthesis rate when assessed over the postprandial period. However, isolated casein dissolved in bovine milk matrix does not modulate myofibrillar protein fractional synthesis rate in older men when compared to isolated casein dissolved in water. Future investigations are warranted to evaluate the clinical relevance of further addition of nutrients to different high quality proteins to maintain the muscle mass in the older population.

\section{Role of the student}

Sarah Reiners was an undergraduate student working under the supervision of Dr. T. A. Churchward-Venne when this report was written. The topic was proposed by 
the supervisor and the raw data were previously generated by the supervisor. The data analysis and calculations and the processing of the results, as well as the formulation of the conclusions and the writing were done by the student.

\section{Acknowledgments}

I would like to thank my supervisors Dr. T. A. Churchward-Venne and Dr. L. Verdijk for their encouragement and support. Further, I would like to thank the whole $M_{3}$ research group for their honest accommodation and their kind explanations.

\section{References}

1. Pennings B, Boirie $\mathrm{Y}$, Senden JM, Gijsen AP, Kuipers H, van Loon LJ. Whey protein stimulates postprandial muscle protein accretion more effectively than do casein and casein hydrolysate in older men. Am J Clin Nutr. 2011;93(5):997-1005.

2. Boirie Y, Dangin M, Gachon P, Vasson MP, Maubois JL, Beaufrere B. Slow and fast dietary proteins differently modulate postprandial protein accretion. Proc Natl Acad Sci U S A. 1997;94(26):14930-5.

3. Fouillet H, Gaudichon C, Mariotti F, Bos C, Huneau JF, Tome D. Energy nutrients modulate the splanchnic sequestration of dietary nitrogen in humans: a compartmental analysis. Am J Physiol Endocrinol Metab. 2001;281(2):E248-60.

4. Park YW. Relative buffering capacity of goat milk, cow milk, soy-based infant formulas and commercial nonprescription antacid drugs. J Dairy Sci. 1991;74(10):3326-33.

5. Report of the Expert Committee on the Diagnosis and Classification of Diabetes Mellitus. Diabetes Care. 2003;26(suppl 1):S5-s20

6. Abumrad NN, Rabin D, Diamond MP, Lacy WW. Use of a heated superficial hand vein as an alternative site for the measurement of amino acid concentrations and for the study of glucose and alanine kinetics in man. Metabolism. 1981;30(9):936-40.

7. Bergstrom J. Percutaneous needle biopsy of skeletal muscle in physiological and clinical research. Scand J Clin Lab Invest. 1975;35(7):609-16.

8. Calbet JA, MacLean DA. Role of caloric content on gastric emptying in humans. J Physiol. 1997;498 ( Pt 2):553-9.

9. Gorissen SH, Burd NA, Hamer HM, Gijsen AP, Groen BB, van Loon LJ. Carbohydrate coingestion delays dietary protein digestion and absorption but does not modulate postprandial muscle protein accretion. J Clin Endocrinol Metab. 2014;99(6):2250-8.

10. Dangin $M$, Boirie $Y$, Guillet C, Beaufrere B. Influence of the protein digestion rate on protein turnover in young and elderly subjects. J Nutr. 2002;132(10):3228S-33S

11. Koopman R, Crombach N, Gijsen AP, Walrand S, Fauquant J, Kies AK, et al. Ingestion of a protein hydrolysate is accompanied by an accelerated in vivo digestion and absorption rate when compared with its intact protein. Am J Clin Nutr. 2009;90(1):106-15. 
12. Bohe J, Low JF, Wolfe RR, Rennie MJ. Latency and duration of stimulation of human muscle protein synthesis during continuous infusion of amino acids. J Physiol. 2001;532(Pt 2):575-9.

13. Cynober LA. Plasma amino acid levels with a note on membrane transport: characteristics, regulation, and metabolic significance. Nutrition. 2002;18(9):761-6.

14. Kimball SR, Jefferson LS. Control of protein synthesis by amino acid availability. Curr Opin Clin Nutr Metab Care. 2002;5(1):63-7.

15. Volpi E, Ferrando AA, Yeckel CW, Tipton KD, Wolfe RR. Exogenous amino acids stimulate net muscle protein synthesis in the elderly. J Clin Invest. 1998;101(9):2000-7.

16. Pennings B, Groen BB, van Dijk JW, de Lange A, Kiskini A, Kuklinski M, et al. Minced beef is more rapidly digested and absorbed than beef steak, resulting in greater postprandial protein retention in older men. Am J Clin Nutr. 2013;98(1):121-8.

17. Mitchell WK, Phillips BE, Williams JP, Rankin D, Lund JN, Smith K, et al. A Dose- rather than Delivery ProfileDependent Mechanism Regulates the "Muscle-Full" Effect in Response to Oral Essential Amino Acid Intake in Young Men. The Journal of Nutrition. 2015;145(2):207-14. 